\title{
Communication
}

\section{Various cationic carriers for in vitro transfection of tumor and endothelial cell lines ${ }^{\star}$}

\author{
Barbara Zemlińska, Aleksander Sochanik, Ewa Missol-Kolka ${ }^{\bowtie}$ and Stanisław Szala \\ Department of Molecular Biology, Center of Oncology-Maria Sktodowska-Curie Memorial \\ Institute, Gliwice, Poland
}

Received: 16 October, 2001; accepted: 14 February, 2002

Key words: cationic carriers, luciferase reporter gene, in vitro transfection

\begin{abstract}
We compared the efficiency of in vitro DNA transfer into selected tumor and endothelial cell lines using complexes of plasmid DNA and cationic carriers: DDAB/DOPE, DC-Chol/DOPE, Arg-Chol/DOPE, Gly-Chol/DOPE, Arg-Gly-Chol/DOPE, BGTC/DOPE, and PEI. The best carriers for transfecting the majority of tested cells lines at optimized carrier-to-DNA weight ratios were PEI and BGTC/DOPE.
\end{abstract}

The feasibility and safety of in vivo cationic carrier-mediated gene transfer have been demonstrated in numerous studies [e.g. 1, 2]. Such transfer has become an effective therapeutic strategy in destroying various cancers, as even transient expression of certain therapeutic genes delivered to either tumor or endothelial cells may be sufficient to bring about tumor destruction [1-3]. Genes hampering development of new vessels within tumor are a suitable example. Modification of endothelial cells with such genes forms the basis of the so-called antiangiogenic strategy in cancer therapy trials [3].

Delivery of therapeutic genes into cells has been achieved using either viral or non-viral techniques [1, 4-6]. Synthetic carriers, such as cationic liposomes or polymers, provide examples of the latter techniques. A major problem plaguing trials with non-viral carriers is their relatively low transfection efficiency, especially in vivo [4, 5]. However, cationic carriers are relatively cheap, simple to use and easy for large-scale preparation [1, 4]. They

\footnotetext{
This study was supported by Grant Z-KBN 004/P04/98 from the State Committee for Scientific Research (KBN, Poland).

${ }^{\otimes}$ Corresponding author: Ewa Missol-Kolka, Department of Molecular Biology, Center of Oncology-Maria Skłodowska-Curie Memorial Institute, Wybrzeże Armii Krajowej 15, 44-101 Gliwice, Poland; tel: (48 32) 278 9698, fax: (48 32) 231 3512, e-mail: ekolka@io.gliwice.pl
}

Abbreviations: see Materials and Methods. 
are non-immunogenic, do not integrate with the host genome and have no size limitation for transferred gene [1, 2, 4].

Optimization of transfection parameters such as DNA amount, carrier-to-DNA weight ratio, transfection buffer or complex incubation time may increase the low efficiencies of gene transfer currently obtainable with cationic carriers [3, 7-11].

The aim of our study was to optimize cationic carrier-to-luciferase plasmid DNA weight ratios in transfection of both tumor and endothelial (refractory to transfection) cells. As carriers for transfection of B16(F10), T-24, HECa 10, HEC PP and BAEC cells, the following cationic liposomes were used: DDAB/DOPE, DC-Chol/DOPE, Arg-Chol/ DOPE, Gly-Chol/DOPE, Arg-Gly-Chol/DOPE, BGTC/DOPE as well as a cationic polymer, PEI. Transfection efficiency was measured by assaying the expression of the luciferase reporter gene.

\section{MATERIALS AND METHODS}

Plasmid DNA. Plasmid pVR1255 containing the luciferase gene under the control of CMV promoter (obtained from Dr. R. Zaugg, Vical Inc., San Diego, CA, U.S.A.) was used. Plasmid DNA preparations were isolated according to Wicks et al. [12] and separated from endotoxin and other contaminants as described by Horn et al. [13].

Cell lines. B16(F10) murine melanoma, T-24 human bladder carcinoma, HECa 10 murine endothelial cells from lymph nodes and HEC PP murine endothelial cells from Peyer's nodules were grown in RPMI 1640 medium (Gibco BRL) with 10\% foetal bovine serum (FBS; Gibco BRL). HECa 10 and HEC PP cells were a gift from Dr. Duś (Institute of Immunology and Experimental Therapy, Wrocław, Poland). Bovine aortic endothelial cells (BAEC, from Clonetics) were grown in ECGM medium (Clonetics) with 2\% FBS. Cul- tures were maintained in a humidified $37^{\circ} \mathrm{C}$ incubator under $5 \% \mathrm{CO}_{2}$.

Cationic carriers. Two cationic lipids were synthesized according to literature data: DC-Chol (3- $\beta$-[ $N$ - $\left(N^{\prime}, N^{\prime}\right.$-dimethylaminoethano)carbamoyl]cholesterol) [14] and BGTC (3- $\beta$-[( $N^{\prime}, N$-diguanidine ethylaminethane)carbamoyl]cholesterol) [15]. The lipids Arg-Chol (cholesteryl $\omega$-BOC-arginine glycinate), Gly-Chol (cholesteryl glycinate) and Arg-GlyChol (cholesteryl arginine glycinate) were synthesized in our laboratory [16]. The cationic lipid DDAB (dimethyldioctadecylammonium bromide) [17] and the cationic polymer PEI (polyethyleneimine) [18] were purchased from Sigma, and DOPE (dioleoylophosphatidylethanolamine) was from Avanti Polar Lipids.

Preparation of polyplexes (PEI-DNA complexes). Aliquots of $2 \mu \mathrm{g}$ of DNA/well in a polystyrene tube were diluted to $100 \mu \mathrm{l}$ with deionized water and adjusted to $150 \mathrm{mM}$ $\mathrm{NaCl}$. PEI (25 kDa) stock solution was prepared as described [18]. PEI suspension was diluted in a separate polystyrene tube to $100 \mu \mathrm{l}$ using deionized water and adjusted to $150 \mathrm{mM} \mathrm{NaCl}$. The separate solutions were gently vortexed and incubated for $10 \mathrm{~min}$ at room temp. The PEI solution was added dropwise to DNA solutions and the transfection mixtures were vortexed and incubated for further $10 \mathrm{~min}$ at room temp.

Preparation of lipoplexes (cationic liposome-DNA complexes). Aliquots of $2 \mu \mathrm{g}$ of DNA/well were diluted in a test tube to $100 \mu \mathrm{l}$ using deionized water (transfection in the presence of serum) or using OPTI-MEM (serum-reduced medium, Gibco BRL) for transfection in medium without serum. Appropriate amounts of cationic carrier suspensions were diluted in polystyrene tubes to $100 \mu \mathrm{l}$ using deionized water or OPTI-MEM and incubated for $45 \mathrm{~min}$ at room temp. Then, DNA aliquots were added dropwise to cationic liposome emulsions and incubated for $15 \mathrm{~min}$ at room temp. 
In vitro transfection. Cells $\left(5 \times 10^{5}\right.$ per well) were grown on 24-well plates. After $24 \mathrm{~h}$ cells were transfected with $2 \mu \mathrm{g} /$ well of pVR1255 plasmid DNA complexed with varying amounts of the cationic carriers. Appropriate transfection medium $(1 \mathrm{ml})$ was used to dilute the prepared polyplexes or lipoplexes which were then added to plated cells. Cultures were incubated for $4 \mathrm{~h}$ at $37^{\circ} \mathrm{C}$. Then, the transfection medium was removed and replaced with $1 \mathrm{ml}$ of growth medium containing $10 \% \mathrm{FBS}$.

Measuring luciferase activity. Twentyfour hours after transfection cells were washed twice with $\mathrm{PBS}^{-}$(standard PBS buffer without $\mathrm{Ca}^{2+}$ and $\mathrm{Mg}^{2+}$ ) and lysed using 150 $\mu$ lysis buffer (Promega). Cell lysates were luminescence units (RLU) per milligram of total extracted protein.

\section{RESULTS AND DISCUSSION}

For each cell line tested, the transfection efficiencies obtained with optimized cationic carrier-to-DNA weight ratios (Table 1) are shown in Fig. 1. The highest luciferase expression $\left(10^{10} \mathrm{RLU} / \mathrm{mg}\right.$ protein) was found for B16(F10) cells transfected using PEI/DNA $0.6: 1(w: w)$. There was no difference in the efficiency of transfection mediated by PEI in the presence or absence of serum. PEI is a polyamine with a very high cationic charge density due to which it constitutes an efficient

Table1. Optimal carrier-to-DNA weight ratios in transfection cells lines with plasmid pVR1255 complexed with cationic carriers.

The cells were transfected with $2 \mu \mathrm{g}$ /well of luciferase gene-containing pVR1255 plasmid DNA complexed with different amounts of cationic liposomes indicated or the cationic polymer PEI. Transfection took place in medium with $10 \%$ FBS (+FBS) or medium without serum (-FBS).

\begin{tabular}{|c|c|c|c|c|c|c|c|c|c|c|}
\hline \multirow{3}{*}{ Carrier } & \multicolumn{10}{|c|}{ Optimal carrier-to-DNA weight ratio } \\
\hline & \multicolumn{2}{|c|}{ B16(F10) } & \multicolumn{2}{|c|}{$\mathrm{T}-24$} & \multicolumn{2}{|c|}{ HEC PP } & \multicolumn{2}{|c|}{ HECa 10} & \multicolumn{2}{|c|}{ BEAC } \\
\hline & $-\mathrm{FBS}$ & $+\mathrm{FBS}$ & $-\mathrm{FBS}$ & $+\mathrm{FBS}$ & $-\mathrm{FBS}$ & $+\mathrm{FBS}$ & $-\mathrm{FBS}$ & $+\mathrm{FBS}$ & $-\mathrm{FBS}$ & $+\mathrm{FBS}$ \\
\hline Arg-Chol/DOPE & $3: 1$ & $7: 1$ & $2: 1$ & $1: 1$ & $2: 1$ & $2: 1$ & $5: 1$ & $7: 1$ & $3: 1$ & $3: 1$ \\
\hline Gly-Chol/DOPE & $3: 1$ & $10: 1$ & $3: 1$ & $2: 1$ & $5: 1$ & $2: 1$ & $2: 1$ & $2: 1$ & $3: 1$ & $3: 1$ \\
\hline Arg-Gly-Chol/DOPE & $3: 1$ & $7: 1$ & $3: 1$ & $3: 1$ & $5: 1$ & $7: 1$ & $3: 1$ & $5: 1$ & $3: 1$ & $1: 1$ \\
\hline $\mathrm{DDAB} / \mathrm{DOPE}$ & $2: 1$ & $3: 1$ & $3: 1$ & $7: 1$ & $3: 1$ & $5: 1$ & $3: 1$ & $5: 1$ & $3: 1$ & $1: 1$ \\
\hline DC-Chol/DOPE & $1: 1$ & $5: 1$ & $2: 1$ & $3: 1$ & $2: 1$ & $5: 1$ & $7: 1$ & $7: 1$ & $3: 1$ & $3: 1$ \\
\hline BGTC/DOPE & $2: 1$ & $5: 1$ & $2: 1$ & $5: 1$ & $3: 1$ & $5: 1$ & $5: 1$ & $5: 1$ & $3: 1$ & $7: 1$ \\
\hline PEI & $0.6: 1$ & $0.6: 1$ & $0.6: 1$ & $0.6: 1$ & $3: 1$ & $0.6: 1$ & $1: 1$ & $0.6: 1$ & $0.6: 1$ & $3: 1$ \\
\hline
\end{tabular}

centrifuged (15000 r.p.m., $15 \mathrm{~min}, 4^{\circ} \mathrm{C}$ ). Luciferase activity was measured using $20 \mu \mathrm{l}$ aliquots of supernatant to which $100 \mu \mathrm{l}$ luciferase substrate (Promega) was added. LUMAT LB 9501/16 luminometer (Berthold) was used. Protein concentration was determined in $10 \mu \mathrm{l}$ aliquots of supernatant using Dye Reagent Concentrate solution (Bio-Rad). Luciferase activity was normalized to relative vector for DNA delivery into cells as it condenses DNA, improves its escape from endocytic vesicles and may even promote transgene transfer from the cytoplasm to the nucleus [4, 18, 19]. Polyethyleneimine was used on its own and demonstrated satisfactory transfection efficiencies in the majority of tumor and endothelial cell lines tested (see Fig. 1). 

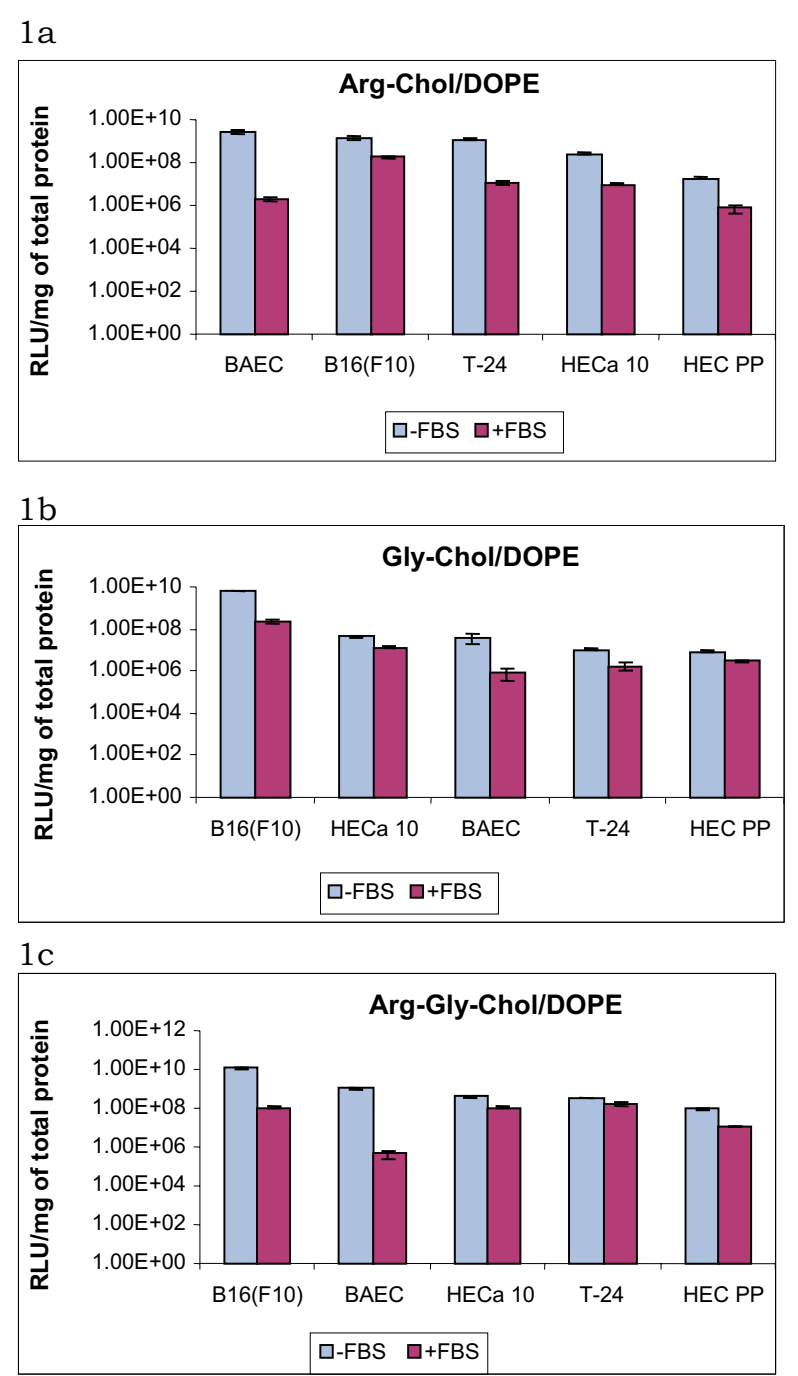

$1 \mathrm{~d}$

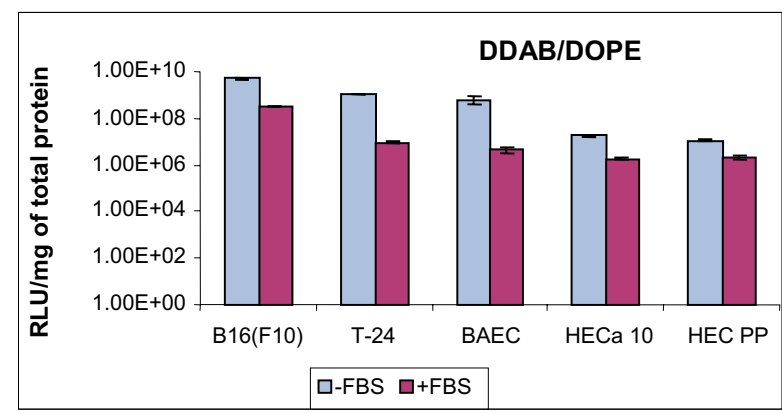

The cationic liposome preparations used in our study contain an electrostatically neutral component, DOPE, as well as lipids featuring cationic cholesterol derivatives (except for DDAB, a detergent). Cholesterol is well known to improve stability of cationic liposomes and to prolong half-life of their complexes with plasmid DNA in circulation [2, 7].
$1 \mathrm{e}$
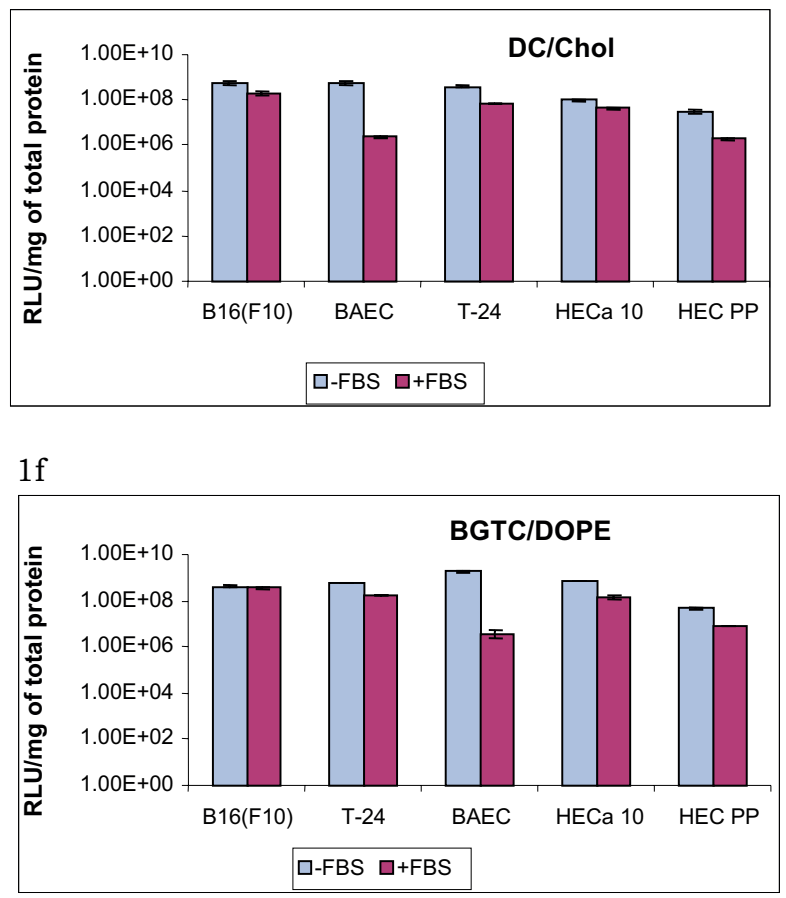

$1 \mathrm{~g}$

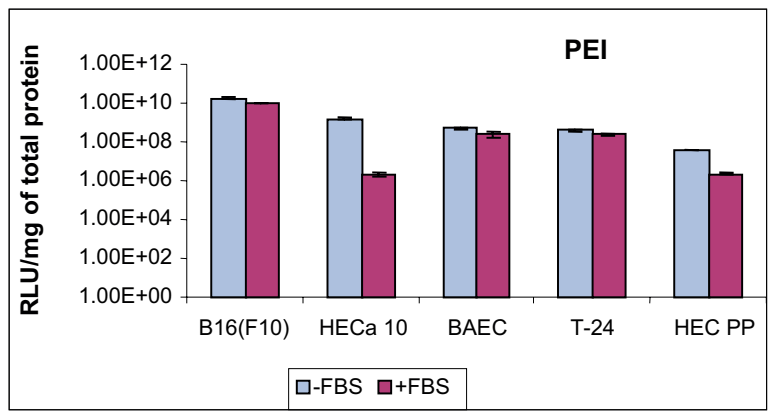

Figure 1. Transfection efficiency cells lines with plasmid pVR1255 containing luciferase gene complexed with cationic carriers at optimal carrier-to-DNA weight ratios.

Luciferase gene expression was measured in cell lysates $24 \mathrm{~h}$ after transfection. Luciferase activity in each sample was normalized to relative luminescence units (RLU) per milligram of total extracted cell protein. Each data point represents mean luciferase activity measured in triplicate $( \pm$ S.D.) at the optimal carrier-to-DNA weight ratios.

Liposomes made of cationic lipids and DOPE usually yield better transfection efficiencies than corresponding cationic lipids alone, because DOPE promotes membrane fusion thus helping in endosome disruption [2, 4, 20]. For- 
mulations of cationic liposomes used had been previously optimized (data not shown). They were as follows: DDAB/DOPE 0.6:1 (w:w), DC-Chol/DOPE 1:1 (w:w), Arg-Chol/DOPE 2:1 (w:w), Gly-Chol/DOPE 2:1 (w:w) Arg-GlyChol/DOPE 2:2:1 (by wt.) and BGTC/DOPE 3:2 (mol:mol).

The majority of the cationic liposomes tested yielded satisfactory transfection levels (see Fig. 1). As expected, we found differences between luciferase expression levels in the cells transfected using serum-containing medium and medium without serum. For all cell lines, the expression of the reporter gene (at the optimized carrier-to-DNA weight ratios) in medium without serum was, on average, one order of magnitude higher $\left(10^{7}-10^{10} \mathrm{RLU} / \mathrm{mg}\right.$ protein) than that obtained in the presence of $10 \%$ serum $\left(10^{5}-10^{8} \mathrm{RLU} / \mathrm{mg}\right.$ protein). Serum presence in the medium usually decreases transfection efficiency achievable with cationic liposomes due to the binding of the negatively charged serum proteins to lipoplexes which prevents binding of the latter to target cells [2, 4].

Transfection efficiency varies between different types of cationic carriers (Fig. 1). It is not known whether these differences are due to different abilities of the cationic lipids tested to form complexes with DNA, or whether they reflect the efficiency of DNA transfer into cells [3, 11]. Under the same conditions, transfection efficiencies using the same carriers differ in various cell types (Fig. 1). Consistently high level of transgene expression was observed for B16(F10) cells. Generally, the efficiency of tumor cell transfection was on average one order of magnitude greater $\left(10^{6}-10^{10} \mathrm{RLU} / \mathrm{mg}\right.$ protein) than that of endothelial cells $\left(10^{5}-10^{9}\right.$ $\mathrm{RLU} / \mathrm{mg}$ protein), especially in serum-containing medium (Fig. 1). This is probably caused by differences in plasma membrane structure between tumor and endothelial cells. Alternatively, it may result from differential uptake ability of carrier-DNA complexes by these cells. High levels of transgene expression following lipofection are obtained only in actively dividing cells [21]. As endothelial cells proliferate much slower than tumor cells, their transfection efficiency is correspondingly lower. Nevertheless, even though endothelial cells are difficult to transfect [3], we show that they can be transfected with acceptable efficiency using cationic carriers (Fig. 1).

Our data demonstrate that all the cationic carriers tested: DDAB/DOPE, DC-Chol/ DOPE, Arg-Chol/DOPE, Gly-Chol/DOPE, Arg-Gly-Chol/DOPE, BGTC/DOPE and PEI are useful reagents for transfecting mammalian cells, both tumor and endothelial. At optimized carrier-to-DNA weight ratios they can provide high transfection levels in such cells. The best carriers for transfecting the majority of the cells tested were the cationic polymer PEI and cationic BGTC/DOPE liposomes.

We thank H. Paterak and M. Krawczyk for their technical assistance.

\section{R E F E R E N C E S}

1. Ledley, F.D. (1995) Hum. Gene Ther. 6, 1129-1144.

2. Gao, X. \& Huang, L. (1995) Gene Ther. 2, 710-722.

3. Fife, K., Bower, M., Cooper, R.G., Stewart, L., Etheridge, C.J., Coombes, R.C., Buluwela, L. \& Miller, A.D. (1998) Gene Ther. 5, 614-620.

4. Li, S. \& Huang, L. (2000) Gene Ther. 7, 31-34.

5. Mountain, A. (2000) Trends Biotechnol. 18, 119-128.

6. Colosimo, A., Goncz, K.K., Holmes, A.R., Kunzelmann, K., Novelli, G., Malone, R.W., Bennett, M.J. \& Gruenert, D.C. (2000) BioTechniques 29, 314-331.

7. Crook, K., Stevenson, B.J., Dubouchet, M. \& Porteous, D.J. (1998) Gene Ther. 5, 137-143. 
8. Armeanu, S., Pelisek, J., Krausz, E., Fuchs, A., Groth, D., Curth, R., Keil, O., Quilici, J., Rolland, P.H., Reszka, R. \& Nikol, S. (2000) Mol. Ther. 1, 366-375.

9. Keogh, M.-C., Chen, D., Lupu, F., Shaper, N., Schmitt, J.F., Kakkar, V.V. \& Lemoine, N.R. (1997) Gene Ther. 4, 162-171.

10. Liu, F., Qi, H., Huang, L. \& Liu, D. (1997) Gene Ther. 4, 517-523.

11. Caplen, N.J., Kinrade, E., Sorgi, F., Gao, X., Gruenert, D., Geddes, D., Coutelle, C., Huang, L., Alton, E.W.F.W. \& Williamson, R. (1995) Gene Ther. 2, 603-613.

12. Wicks, I.P., Howell, M.L., Hancock, T., Kohsaka, H., Olee, T. \& Carson, D.A. (1995) Hum. Gene Ther. 6, 317-323.

13. Horn, N.A., Meek, J.A., Budahazi, G. \& Marquet, M. (1995) Hum. Gene Ther. 6, 565-573.

14. Gao, X. \& Huang, L. (1991) Biochem. Biophys. Res. Commun. 179, 280-285.

15. Vigneron, J.P., Oudrhiri, N., Fauquet, M., Vergely, L., Bradley, J.-C., Basseville, M.,
Lehn, P. \& Lehn, J.-M. (1996) Proc. Natl. Acad. Sci. U.S.A. 93, 9682-9686.

16. Sochanik, A. (1999) Ph.D. Thesis. Institute of Immunology and Experimental Therapy, Wrocław, Poland, 20-22.

17. Rose, J.K., Buonocore, L. \& Whitt, M.A. (1991) BioTechniques 10, 520-525.

18. Abdallah, B., Hassan, A., Benoist, C., Goula, D., Behr, J.-P. \& Demeneix, B. (1996) Hum. Gene Ther. 7, 1947-1954.

19. Boussif, O., Lezoualc'h, F., Zanta, M.A., Mergny, M.D., Scherman, D., Demeneix, B. \& Behr, J.-P. (1995) Proc. Natl. Acad. Sci. U.S.A. 92, 7297-7301.

20. Mahato, R.I., Takakura, Y. \& Hashida, M. (1997) Crit. Rev. Ther. Drug Carrier Systems. 14, 133-172.

21. Brunner, S., Sauer, T., Carotta, S., Cotten, M., Saltik, M. \& Wagner, E. (2000) Gene Ther. 7, 401-407. 